\section{Quality of life in patients with melasma in Turkish women}

\author{
Hacer Uyanikoglu, ${ }^{1}$ Mustafa Aksoy ${ }^{2}$ \\ ${ }^{1}$ Department of Obstetrics and \\ Gynecology; ${ }^{2}$ Department of \\ Dermatology, Harran University \\ Medical Faculty, Sanliurfa, Turkey
}

\begin{abstract}
The aim of this study was to determine the impact of melasma on quality of life (QoL) using the dermatology life quality index (DLQI) questionnaire in a group of outpatients. This study is questionnairebased. A total of 101 Turkish women suffering from melasma, who themselves were able to understand and complete the Turkish version of the DLQI questionnaire, were enrolled. This questionnaire included 10 questions; each of each was scored on a scale of $0-3$, with a maximum score of 30 . The data were analyzed after the results had been collated and the higher the DLQI score, the poorer the QoL. The participants' mean age was $29.53 \pm 6.87$ years, and mean DLQI score was $6.02 \pm 4.94$. When we divided the participants into two subgroups according to age, the DLQI scores for younger and older individuals were $7.44 \pm 4.99$ and $4.33 \pm 4.36$, respectively $(\mathrm{P}=0.001)$. When the melasma area and severity index (MASI) score was used, participants with mild and moderate disease had mean DLQI scores of $5.80 \pm 4.72$ and $7.11 \pm 5.90$, respectively. No patient had severe disease. Melasma might affect the participants' QoL, especially that of the younger individuals, in our study population.
\end{abstract}

\section{Introduction}

Melasma is a common disorder of acquired hyperpigmentation. It is characterized by irregular macules on sun-exposed areas of the face mainly the cheeks, forehead, upper lip, nose, and chin. ${ }^{1}$

Although the clinical and histological features of melasma are similar in both genders, the disorder is more commonly observed in females of reproductive age than in males of the same age $(90 \%$ vs $10 \%){ }^{2}$ The precise etiology of melasma is not well known, and statistical data regarding its incidence are lacking. ${ }^{3}$ However, it has been shown that various risk factors, such as ultraviolet (UV) light, genetic pre- disposition, pregnancies, oral contraceptives (OC), hormonal therapies, thyroid autoimmunity, cosmetics ingredients, and phototoxic drugs are involved. ${ }^{4}$ Melasma is more common in locations that experience high-intensity UV radiation, such as Asia and Latin America, and it occurs in up to $10.7 \%$ of pregnant women. ${ }^{5,6}$

The measurement of quality of life (QoL) is increasingly becoming part of the total assessment of a patient's health, in both the clinical and the research settings. It is defined as the capacity to perform daily activities, and provides a more detailed knowledge of the health of the patient. ${ }^{7}$

Our city, Sanliurfa, is in the southeast region of Turkey, where exposure to the sunlight is excessive. At the same time, the number of pregnancies is higher in this region than in the rest of Turkey. ${ }^{8}$ Nevertheless, there was no study researching impact of melasma on Turkish women. Therefore, we investigated the clinical factors associated with melasma and used the DLQI questionnaire ${ }^{7}$ to assess its impact on the QoL of Turkish women living in the southeast region of the country.

\section{Compliance with ethical standards}

All procedures performed in studies involving human participants were in accordance with the ethical standards of the institutional and/or national research committee and with the 1964 Helsinki declaration and its later amendments or comparable ethical standards.

Informed consent was obtained from all individual participants included in the study.

\section{Materials and Methods}

This questionnaire-based study was performed in 101 melasma patients at the Departments of Gynecology and Dermatology, Harran University Medical Faculty, Sanliurfa, Turkey, between January 2016 and December 2016. The study protocol was approved by the Hospital Ethical Committee, and informed consent was obtained from all participants.

The data collected included demographic and clinical parameters, such as age, family history, duration of melasma, number of pregnancies, and the use of hormonal contraceptives. The clinical distribution of melasma was scored as Fitzpatrick phototypes [type I, always burns, never tans; type II, always burns, tans minimally; type III, burns moderately, tans gradually (light brown); type IV, burns minimally, tans well (moderate brown); type $\mathrm{V}$, rarely burns, tans
Correspondence: Hacer Uyanikoglu, Harran University, School of Medicine, Department of Obstetrics and Gynecology, Yenisehir Campus, 63300, Sanliurfa, Turkey.

Tel.: +94.143183097 Fax: +94.0414.318319. E-mail: huoglu@hotmail.com

Key words: Quality of life; Turkish women; melasma.

Acknowledgments: we would like to thank all the subjects who participated in this questionnaire. Also we thank Professor Tevfik Sabuncu for his supporting to statistical analyses.

Conflict of interest: the authors declare no potential conflict of interest.

Received for publication: 3 August 2017.

Accepted for publication: 18 September 2017.

This work is licensed under a Creative Commons Attribution-NonCommercial 4.0 International License (CC BY-NC 4.0).

(C) Copyright H. Uyanikoglu and M. Aksoy, 2017 Licensee PAGEPress, Italy

Dermatology Reports 2017; 9:7340

doi:10.4081/dr:2017.7340

darkly (black brown); type VI, never burns, tans dark black (black)]. ${ }^{9}$ Melasma area and severity index (MASI) score was calculated by subjective assessment of the following three factors: area (A) of involvement, darkness (D), and homogeneity $(\mathrm{H})$, and rated on a scale of 0 - 4 ( $0=$ absent; $1=$ slight; $2=$ mild; $3=$ marked; and 4=maximum). The MASI score was recorded according to the literature (total MASI score: forehead 0.3 $(\mathrm{D}+\mathrm{H}) \mathrm{A}+$ right malar $0.3(\mathrm{D}+\mathrm{H}) \mathrm{A}+$ left malar $0.3(\mathrm{D}+\mathrm{H}) \mathrm{A}+\operatorname{chin} 0.1(\mathrm{D}+\mathrm{H}) \mathrm{A}){ }^{10}$ The total score ranged from $0-48$, with higher scores indicating more severe disease.

The inclusion criteria were clinical diagnosis of melasma, sufficient physical and mental capacity, age of at least 18 years, and the ability to speak and read Turkish. The exclusion criteria were male gender, pregnant women, age of below 18 years, systemic disorders (such as adrenal or thyroid disorders), and other dermatological disorders that could hinder the evaluation of melasma lesions, such as systemic lupus erythematosus and post-inflammatory hyperpigmentation.

All the participants were instructed to complete a DLQI questionnaire that consisted of 10 questions, and were asked to score all of these questions on a scale from $0-3$, with $0=$ not at all, $1=$ a little, $2=a$ lot, and $3=$ very much. ${ }^{11}$ The total score ranged from 0-30. The higher score, the poorer the QoL. 


\section{Statistical analysis}

The data were analyzed with SPSS version 20. Mean and standard deviation (SD) were used for quantitative variables (e.g., age, gravidity, DLQI scores). For qualitative variables like frequency and percentage were calculated. Data were stratified for severity of melasma (MASI score $=0-16$, $17-32,33-48)$. A $P$ value of $<0.05$ was considered significant.

\section{Results}

A total of 111 patients participated in this questionnaire-based study. Ten individuals with melasma were excluded because of lower age ( $<18$ years), pregnancy, and other systemic disorders. Ultimately, 101 individuals with melasma completed the questionnaire and were enrolled in the analyses.

The mean age of the study population was $29.53 \pm 6.87$ years, and all participants were female. The most common Fitzpatrick skin phototypes were III and IV $(50.5 \%$ and $38.6 \%$, respectively). The mean duration of disease was $18.74 \pm 10.2$ months. The demo-

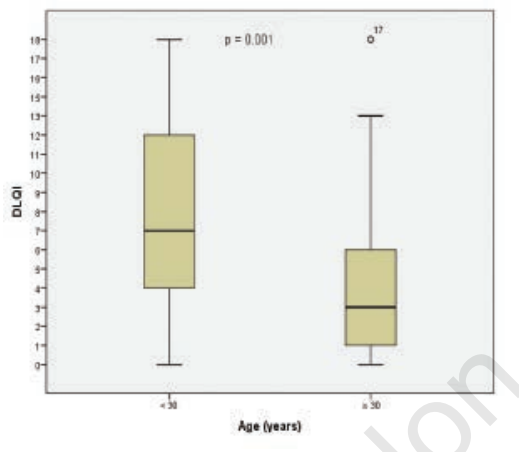

Figure 1. DLQI scores between the younger and older age groups.
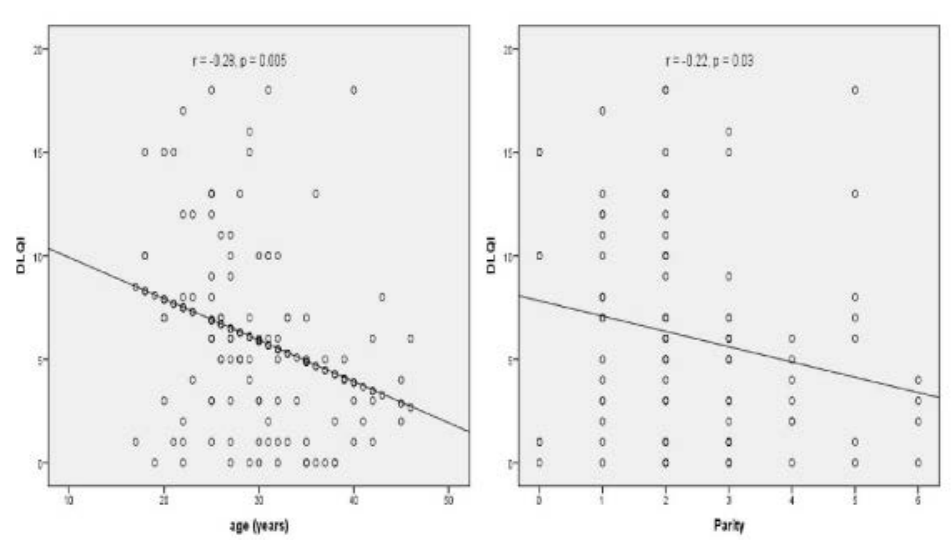

Figure 2. Negative correlations between DLQI score and age and parity.

graphic and clinical characteristics of the study participants are presented in Tables 1 and 2.

According to melasma severity, 81 patients had mild disease, having a MASI score from $0-16$, and 20 patients had moderate disease, having a MASI score of 17-32 (the mean scores were $7.65 \pm 3.47$ and $17.9 \pm 2.15$, respectively). No patient had severe disease (a MASI score of 33-48).

The mean DLQI score of all patients was $6.02 \pm 4.94$. A comparison of the mean DLQI scores between those aged $<30$ years and those aged $\geq 30$ years was made, and a significant difference between the younger and older age groups was observed (7.44 \pm 4.99 and $4.33 \pm 4.36$, respectively; $\mathrm{P}=0.001$; Figure 1). The participants with a mild MASI score had a mean DLQI score of $5.80 \pm 4.72$, and those with a moderate MASI score had a mean DLQI score of $7.11 \pm 5.90$. This indicates a slight but statistically insignificant increase in DLQI score in the participants with more severe disease ( $\mathrm{P}>0.05$; Table 3$)$.

In the correlation analysis, the DLQI score was significantly negatively correlated with age and parity ( $\mathrm{r}:-0.28, \mathrm{P}=0.005 ; \mathrm{r}$ : $-0.22, \mathrm{P}=0.03$, respectively; Figure 2). Similarly, a positive correlation between DLQI score and duration of disease was observed ( $\mathrm{r}$ : 0.28, $\mathrm{P}=0.004$; Figure 3). However, no correlation between the MASI score and age, gravida, DLQI, family history, OC use, and duration of disease was identified (all $\mathrm{P}>0.05$ ).

\section{Discussion and Conclusions}

It has been shown that melasma is a chronic, recurrent skin disorder that may result in deteriorations in patients' QoL in different populations. ${ }^{6,12,13}$ We firstly reported an assesment of QoL in Turkish women

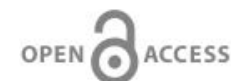

[Dermatology Reports 2017; 9:7340]
Table 1. Demographic and clinical characteristics of the study participants.

$\mathrm{N}=101($ mean $\pm \mathrm{SD})$

\begin{tabular}{lc} 
Age (year) & $38.43 \pm 6.75$ \\
Gravida (n) & $3.44 \pm 1.56$ \\
\hline Parity (n) & $2.45 \pm 1.43$ \\
Duration of disease (month) & $18.74 \pm 10.2$ \\
\hline MASI & \\
$0-16$ & $7.65 \pm 3.47$ \\
$17-32$ & $17.9 \pm 2.15$ \\
$33-48$ & 0 \\
\hline
\end{tabular}

SD, standard deviation; MASI, melasma area and severity index DLQI, dermatology life quality index.

Table 2. Demographic and clinical characteristics of the study participants.

\begin{tabular}{|c|c|}
\hline & $\mathrm{N}=101(\%)$ \\
\hline $\begin{array}{c}\text { Age (year) } \\
<30 y \\
\geq 30 y\end{array}$ & $\begin{array}{l}54.5 \\
45.5\end{array}$ \\
\hline $\begin{array}{c}\text { Marital status } \\
\text { Single } \\
\text { Married }\end{array}$ & $\begin{array}{l}3.03 \\
98.9\end{array}$ \\
\hline $\begin{array}{l}\text { Fitzpatrick skin } \\
\quad 2 \\
3 \\
4\end{array}$ & $\begin{array}{l}10.9 \\
50.5 \\
38.6\end{array}$ \\
\hline OC use & 26.7 \\
\hline Family history & 78.2 \\
\hline
\end{tabular}

OC, oral contraceptive.

Table 3. The mean DLQI score according to severity of disorder (using MASI).

$\begin{array}{lcc}\begin{array}{l}\text { Severity } \\ \text { of disease }\end{array} & \begin{array}{c}\text { DLOI } \\ (\text { mean } \pm \text { SD })\end{array} & \text { P } \\ \text { Mild } & 5.80 \pm 4.72 & \text { NS } \\ \text { Moderate } & 7.11 \pm 5.90 & \text { NS }\end{array}$

Severe

Total sample

\section{$6.02 \pm 4.94$}

MASI, melasma area and severity index; SD, standard deviation; DLQI, dermatology life quality index.

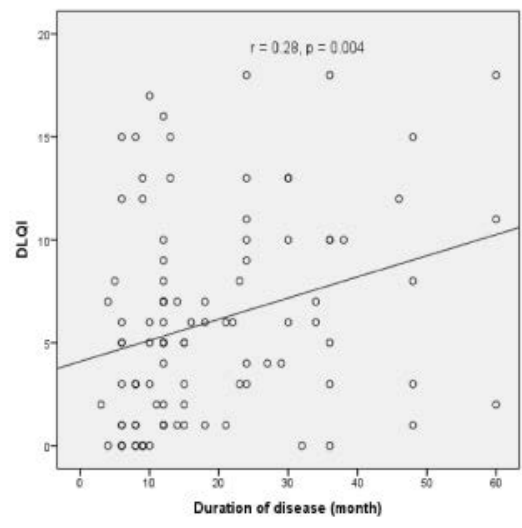

Figure 3. A positive correlation between DLQI score and duration of disease. 
with melasma. Several studies have shown that the mean age of people with melasma is $36-40$ years. ${ }^{11,12}$ In the present study, the mean age of the participants was $29.53 \pm 6.87$ years, this difference may be due to racial, cultural, and social variations in different countries. In our population, the QoL of older women was less affected by melasma than that of the younger group. This was consistent with the findings of Ali et al. and Balkrishnan et al., who observed that melasma patients aged 20-30 years were more affected than patients aged 46-55 years. ${ }^{11,14}$ Therefore, we believe that younger patients with melasma might need more intensive medical care. However, unnecessary tests and intensive medical care are not recommended for pregnant women with melasma, in order to avoid further stress for these patients and because of the transient character of gestational melasma. ${ }^{15}$

The hormonal link to melasma has not been clearly defined; some studies have noted the onset or worsening of disease with pregnancy or OC use. ${ }^{16,17}$ We observed OC use in $26.7 \%$ of our patients, which was consistent with previous studies that showed a prevalence of $8-29 \%$ with regard to $\mathrm{OC}$ use in melasma patients. Although we did not assess the relationship between OC use and the onset of melasma, we observed that $\mathrm{OC}$ use was not associated with melasma severity. However, these data may be insufficient as a result of some limitations of the study design, such as a low patient number and low duration of use of OC.

Although several quantitative measurements (e.g., Mexameter, chromameter) may be used to evaluate melasma severity, we used only MASI scoring in the present study because there is no significant difference between these methods. ${ }^{13}$ Our city (Sanliurfa) is in the southeast region of Turkey and the number of sunny-days and the rate of pregnancies are higher than in the rest of the country. ${ }^{8,18}$ Nevertheless, we observed mild melasma severity and a low DLQI score in most of our participants, which may be explained by the fact that almost all of them were protected from the sun, because they wore a traditional headscarf and stayed at home (i.e., they were housewives). Some studies have shown that working women have more stress-related disorders than housewives. ${ }^{19,20}$ Therefore, we believe that our participants might have been less exposed to stres, affecting their QoL results.

The mean DLQI score is $6.02 \pm 4.94$ in the present study, which was compatible with the findings of Farag et al. from Egypt and with Harumi et al. from Singapore
(5.8 $\pm 3.8,4.5 \pm 5$, respectively), but opposite to those of Ikino et al. from Brazil $(34.4 \pm 13.5){ }^{12,13,21}$ The present study revealed that people suffering from more advanced disease had a slightly higher, but statistically insignificant, mean DLQI score, which was also observed by Farag et al. and Balkrishnan et al. ${ }^{11,12}$ However, Arellano et al. and Ali et al. showed a strong correlation between DLQ1 score and severity of melasma. ${ }^{14,22}$

Previous studies have shown that melasma that is related to a family history, might affect melasma appearance time in some populations. ${ }^{23}$ A multicenter study indicated that patients with a family history of melasma were younger at melasma onset than those without a family history of the disorder. ${ }^{24}$ In contrast, Ikino et al. found no familial relationship in the patients they studied. ${ }^{21}$ The majority of participants $(78.2 \%)$ in the present study had a familial history of melasma. Although we did not assess the relationship between time of melasma onset and family history, we observed no correlation between family history and MASI and DLQI scores.

In conclusion, the present study showed that melasma at a lower age, and with a longer duration, was associated with a greater reduction in QoL in Turkish women. Further comprehensive studies are required to better understand the effect of this frequent skin disorder on QoL.

\section{References}

1. Sheth VM, Pandya AG. Melasma: a comprehensive update: part I. J Am Acad Dermatol 2011;65:689-97.

2. Sarkar R, Puri P, Jain RK, et al. Melasma in men: a clinical, aetiological and histological study. J Eur Acad Dermatol Venereol 2010;24:768-72.

3. Knott L. Chloasma (Melasma) [online] 2009 [cited 2009 May 31]. Available from: http://www.patient.co.uk/showdoc/4000215 2/

4. Grimes PE, Yamada N, Bhawan J. Light microscopic, immunohistochemical and ultrastructural alterations in patients with melasma. Am J Dermatopathol 2005;27:96-101.

5. Perez M, Luke J, Rossi A. Melasma in Latin Americans. J Drugs Dermatol 2011;10:517-23.

6. Hexsel D, Rodrigues TC, Dal'Forno T, et al. Melasma and pregnancy in southern Brazil. J Eur Acad Dermatol Venereol 2009;23:367-8.

7. Dogramaci AC, Havlucu DY, Inandi T, et al. Validation of a melasma quality of life questionnaire for the Turkish language: the MelasQoL-TR study. J Dermatolog Treat 2009;20:95-9.

8. Uyanikoglu H, Karahan MA, Turp AB, et al. Are multiple repeated cesarean sections really as safe? J Matern Fetal Neonatal Med 2017;30:482-5.

9. Pathak M, Nghiem P, Fitzpatrick Th. Acute and chronic effects of the sun. In: Fitzpatrick Th, ed. Fitzpatrick's dermatology in general medicine, 5th edn. New York: McGraw-Hill; 1999. pp 1598-1607.

10. Kimbrough-Green CK, Griffiths CE, Finkel LJ, et al. Topical retinoic acid (tretinoin) for melasma in black patients. A vehicle-controlled clinical trial. Arch Dermatol 1994;130:727-33.

11. Balkrishnan R, McMichael A, Camacho F, et al. Development and validation of a health related quality of life instrument for women with melasma. $\mathrm{Br} \mathrm{J}$ Dermatol 2003;149:572-7.

12. Farag A, Sabry H, Alam M. Melasma and its impact on health related quality of life (HRQoL) in Egyptian women before and after treatment with a quadruple combination serum (hydroquinone $4 \%$, kojic acid $1 \%$, lycolic acid $6 \%$ and ascorbic acid 2\%). J Pan Arab League Dermatol 2007;18:17-30.

13. Harumi O, Goh CL. The effect of melasma on the quality of life in a sample of women living in Singapore. J Clin Aesthet Dermatol 2016;9:21-4.

14. Ali R, Aman S, Nadeem M, et al. Quality of life in patients of melasma. J Pakistan Assoc Dermatol 2013;23:1438.

15. Tyler KH. Physiological skin changes during pregnancy. Clin Obstet Gynecol 2015;58:119-24.

16. Lieberman R, Moy L. Estrogen receptor expression in melasma: results from facial skin of affected patients. J Drugs Dermatol 2008;7:463-5.

17. Maeda K, Naganuma M, Fukuda M, et al. Effect of pituitary and ovarian hormones on human melanocytes in vitro. Pigment Cell Res 1996;9:204-12.

18. Demirkan S, Gündüz Ö, Sayan CD. Retrospective analysis of endemic melasma patients. Dermatol Rep 2017;9:7027.

19. Nyberg A, Peristera P, Westerlund H, et al. Does job promotion affect men's and women's health differently? Dynamic panel models with fixed effects. Int $\mathrm{J}$ Epidemiol 2016 [Epub ahead of print].

20. Bener A, Gerber LM, Sheikh J. Prevalence of psychiatric disorders and associated risk factors in women during their postpartum period: a major public 
health problem and global comparison. Int J Womens Health 2012;4:191-200.

21. Ikino JK, Nunes DH, Silva VP, et al. Melasma and assessment of the quality of life in Brazilian women. An Bras Dermatol 2015;90:196-200.

22. Arellano I, Leon G, Luna C. Quality of life in Mexican patients with melasma. Cosmet Dermatol 2006;5:343-5.

23. Misery L, Schmitt AM, Boussetta S, et al. Melasma: measure of the impact on quality of life using the French version of MELASQOL after cross-cultural adaptation. Acta Derm Venereol
2010;90:331-2.

24. Hexsel D, Lacerda DA, Cavalcante AS, et al. Epidemiology of melasma in Brazilian patients: a multicenter study. Int J Dermatol 2014;53:440-4. 